International Journal of Child, Youth and Family Studies (2014) 5(2): 240-257

\title{
STANDING ON THE SHOULDERS OF GIANTS: NARRATIVE PRACTICES IN SUPPORT OF FRONTLINE COMMUNITY WORK WITH HOMELESSNESS, MENTAL HEALTH, AND SUBSTANCE USE
}

\section{Brian Dean Williams and Barbara Baumgartner}

\begin{abstract}
In the context of starting a Housing First Assertive Community Treatment (ACT) team, the authors describe their use of Narrative Therapy and Narrative Practices while working alongside individuals facing problems with homelessness, mental health challenges, and substance use. As many front line community workers responding to such problems are not trained counsellors, the authors provide an overview to Narrative Therapy, its key concepts, and how workers might use Narrative Practices as a nonexpert, anti-oppressive, and social justice response. To illustrate the concepts and how they translate into everyday conversations with workers, Roy, a participant of the ACT program, shares his story of resistance to the influences of stigma and substances. Roy also offers a reflection on this paper. Practice questions are suggested to support alternative story development, and the relevance for child, youth, and family work is suggested.
\end{abstract}

Keywords: narrative therapy, narrative practices, housing first, assertive community treatment, ACT, substance use, addictions, mental illness, mental health, homelessness

Brian Dean Williams, MA, CCC, is a therapist currently in private practice, $204-402$ West Pender Street, Vancouver B.C., Canada, V6B 1 T6.

E-mail: connect@briandeanwilliams.com

Barbara Baumgartner, MSW, RCSW, is a social worker and counsellor currently working in Brisbane, Australia. E-mail: barb.baumgartner@gmail.com 
In 1676, Isaac Newton wrote to his rival Robert Hooke: "If I have seen further, it is by standing on ye shoulders of giants" (Turnbull, 1959, p. 416). We had similar experiences in our work as members of an Assertive Community Treatment (ACT) Team, working alongside participants seeking solutions to homelessness and mental health issues in Vancouver, Canada. Through front line work in this project, we learned much by witnessing individuals working to overcome homelessness, mental health challenges, and substance use dilemmas. We discovered that the knowledge and lived experiences of program participants informed our ideas and practices, more so than what we learned from school and textbooks. In this sense, we truly do stand on the shoulders of giants. Thus, our aim is to share with others who do front line relational work what we learned from program participants, utilizing key concepts of Narrative Therapy and Narrative Practice. We hope that this will be useful to others working with families and individuals in response to similar problems.

Both authors were members of the RainCity ${ }^{1}$ Housing First Assertive Community Treatment (ACT) Team in Vancouver, British Columbia, which was one branch of the At Home / Chez Soi research demonstration project conducted by the Mental Health Commission of Canada $^{2}$. Beginning in 2009 in five cities across the country, the At Home / Chez Soi study looked into solutions to chronic homelessness for those diagnosed with mental illness by comparing Assertive Community Treatment (ACT), Intensive Case Management (ICM), and congregate housing interventions, to a treatment-as-usual cohort. We are not writing about the results of this research, but rather our lived experiences and what we learned in providing the services $^{3}$.

Our team's role in implementing one of the experimental conditions was to provide housing, mental health, primary health, and substance use services for 90 participants assessed to have "severe mental health issues" through a combination of Housing First and Assertive Community Treatment models. These models were based on the work of the Pathways to Housing organization located in New York City (Tsemberis, 2010). Housing First "is a recoveryoriented approach based on client choice. It gives people who are homeless and living with mental health issues immediate access to independent housing through rent subsidies and mental health supports such as Assertive Community Treatment (ACT) or Intensive Case Management (ICM)” (Mental Health Commission of Canada, 2012). According to Tsemberis (2010), Housing First is based on the belief that "housing is a basic human right rather than something people with mental illness have to earn or prove they deserve by being in treatment" (p. 18). This stands in stark contrast to the more conventional "treatment first" approach to homelessness. ACT is an extensively documented and evidence-based model that has been used since the 1970s as a community-based solution for severe mental illness (Matejkowski \& Draine, 2009, p. 6). In this

\footnotetext{
${ }^{1}$ RainCity is a non-profit agency in Vancouver that specializes in providing innovative services to people struggling with homelessness, with the vision of "a home for every person". Home, with respect to the ACT program, means a market apartment in a neighbourhood of the person's choice.

${ }^{2}$ See www.mentalhealthcommission.ca

${ }^{3}$ For more information on the early findings of the At Home / Chez Soi study, refer to http://www.mentalhealthcommission.ca/English/node/775?terminitial=23
} 
International Journal of Child, Youth and Family Studies (2014) 5(2): 240-257

model, people are provided with an array of professional services to choose from, provided by a transdisciplinary team. In addition, people have a choice of the neighbourhood and type of housing that fits best for them, with no conditions attached to it aside from a commitment to see the team a minimum of once per week. Since housing was not contingent on treatment or medication, participants had a choice of which mix of services, if any, they chose to access. With support from Colin Sanders (2007), Stephen Madigan (2011), and Vikki Reynolds (2010), the authors integrated Narrative Therapy and Narrative Practices into their work within the Housing First ACT model.

\section{Roy's Story}

To set the stage for our work, as well as to centre insider knowledge ${ }^{4}$, we would like to introduce Roy, one of the "giants" on whose shoulders we stand. Roy, a participant of the ACT program, agreed to have his story contribute to this paper. Roy is 37 years old and has 22 years of insider experience with homelessness, substance use, and the mental health system. He grew up in a small city outside of Vancouver, and has experienced homelessness three times in his life, including a seven-year stretch that ended when he became a participant in our program in 2010. Roy has been diagnosed as "schizophrenic" and "schizoaffective", although he does not invest in these labels. He has extensive experience with mental health programs, criminal justice, hospitals, homeless shelters, drop-in centres, and street culture.

Roy recently said: “To tell you the truth I didn't think I'd live past 25 ... on the road I was headed on, 25 is a big feat. Now here I am at 37, finding my stride”. Since becoming a participant with the RainCity ACT Team in early 2010, Roy's physical and mental health has significantly improved, he has been hospitalized much less often, and his substance use patterns have changed:

My drug use has come down to a minimum, maybe $\$ 40$ every two days - it's gone down quite a bit. When you get away from the streets, the dope scene, you start thinking about other things - I busk for cigarettes and groceries. You start looking for other options like construction safety officer, get my first aid, maybe get a small trade ticket.

Roy has been able to reconnect with one of his passions, music, and regularly busks in public with his acoustic guitar. Such outcomes reflect the intentions of the program, which are to provide housing and tenancy support, and to support the person in making their own choices of when and how to change their relationship with substances, pursue educational or vocational goals, or explore psychiatric treatment.

\section{What are Narrative Therapy and Narrative Practice?}

Narrative Therapy is based on the ideas of Michael White and David Espton (White \& Epston, 1990), which they began developing and publishing in the 1970s and 1980s. More

\footnotetext{
${ }^{4}$ Insider knowledge: the understandings and skills gained from being a member of a particular community, and having experiences particular to that community (Anderson \& Burney, 2004, as cited in Tilsen, 2013, p. xviii)
} 
International Journal of Child, Youth and Family Studies (2014) 5(2): 240-257

recently, many people have also contributed to the body of work known collectively as Narrative Practices or Narrative Community Work (Dulwich Centre Publications, n.d.). Narrative Therapy is unique in that it is not based in the tradition of psychology, but is rooted in ideas of social work, anthropology, literary criticism, feminism, and queer theory (Madigan, 2011, p. 12). Such non-individualizing and anti-oppressive ideas have created a valuable theoretical lens through which the contexts of problems are examined collaboratively with the client. Using the metaphor of story, Narrative Therapy considers how identity is created through the telling and retelling of stories within the contexts of class, race, sexuality, gender roles, and culture (Madigan, 2011). In this sense, the ways in which we talk about people and the problems they are experiencing do not just reflect reality, they begin to construct and become reality (Freedman \& Combs, 1996; White \& Epston, 1990).

As a deeply respectful approach that centres the person as the expert in his or her own life, Narrative Therapy is particularly well suited to collaborative work. Drawing on the ethics and emphases of Narrative Therapy, Narrative Practices, also known as Narrative Community Work or Narrative Approaches, have recently been used outside of therapy offices in day-to-day engagement with homelessness, mental health challenges, and substance use dilemmas (Fraenkel, Hameline, \& Shannon, 2009).

While Narrative Therapy purposefully examines the context of problems, it simultaneously seeks to examine the person's or community's response to problems. When it comes to problems such as poverty or mental illness, a person's response to the problem (such as spending one's monthly income on substances instead of food or yelling back at voices), usually gets inadvertently ignored or pathologized by service providers (Becoming An Insider group members, personal communication, n.d.). This only serves to further discount the person's own wisdom of the problem and its tactics. For example, here is the way one group member explained the illogic of budgeting in the context of poverty:

If I only get money once a month and I know that there is no way that the money can last the entire month, what's the point of even trying? I might as well spend it and have one or two weeks of food and comfort. I can always figure out how to get by the last couple weeks. (Becoming An Insider group meeting, circa 2011)

This observation aptly sums up the irrational system response of teaching "budgeting skills" to people whose income is well below the poverty line. By renaming the problem as one of budgeting, the responsibility shifts onto the individual, rather than holding society and government accountable.

\section{How is Narrative Therapy Relevant to Community Work?}

The principles and practices of Narrative Therapy offer rich possibilities not only for narrative therapists, but also for front line community workers. Working within institutions, many conditions exist to support the blaming of individuals for complex problems like homelessness, substance use, and mental illness. White and Epston (1990) write: “Those analyses of power that have appeared in the therapy literature have traditionally represented it in individual terms, such as a biological phenomenon that affects the individual psyche or as 
individual pathology that is the inevitable outcome of early traumatic personal experiences” (pp. 18-19). For instance, using prevailing psychological and psychiatric language tends to pathologize the individual as the source of the problem, by referring to someone primarily by their diagnosis. We may read in a person's file: “Nancy is a Borderline who acts out against other residents on the ward", rather than "Nancy is a person who has been diagnosed with Borderline Personality Disorder" or "Nancy describes herself as someone who struggles with establishing limits in her relationships”. By decontextualizing problems from the social, political, economic, and/or historical influences that support them, it becomes easier for helping professionals to conceive of problems as originating within individual experience.

Narrative Therapy draws strongly on the work of French social theorist Michel Foucault (1980), who suggests "that we are subject to power through normalizing truths around our lives and relationships” (as cited in White \& Epston, 1990, p. 19). Foucault viewed power and knowledge as inseparable, and the ability to define and categorize human experience as one of the primary exercises of power since the 17th century, including the objectification and scientific classification of individual bodies. ${ }^{5}$

When we speak about Narrative Therapy and Narrative Practices with community workers, many realize that they are already operating from a similar set of ethics and practices, but did not have the language or framework to support this way of working. Sometimes they have been using these skills in underground ways, for example, by practicing covert compassion, refusing to pathologize individuals in client files, or inviting people to attend the "case" conferences where their treatment is discussed. In this sense, we view our trainings as acts of solidarity (polanco, 2011; Reynolds, 2010) and community building, rather than bestowing our expert knowledge on under-trained or under-qualified people.

The RainCity Housing First ACT program is not the only group in Canada using Narrative Practice. At an agency level, the Phoenix Youth Programs (PYP), a multi-service agency for homeless youth in Halifax, Canada, has been integrating Narrative Practice into their delivery of residential, drop-in, employment, prevention, and shelter programs (Hartman, Little, \& Ungar, 2008). In 2005 PYP, through an examination of its practices, began to co-author alternative stories of youth's lives by meeting them “where they're at”, drawing greater attention to unique outcomes and involving youth in transmitting their stories between workers, agencies, and their families (Hartman et al., 2008). Peak House in Vancouver, Canada, has also been a leader in applying Narrative Therapy principles in its provision of residential recovery services for young people (Sanders, 1998, 2007). Similarly, Fraenkel and colleagues (2009) have written specifically about applying Narrative Practice to group work with families experiencing homelessness in three New York City shelters. In this context, Narrative Practice emerged as a helpful approach in part:

because with its focus on the constraining effects of language and imagery on identity, narrative therapy seemed uniquely suited to address the impact of stigmatizing language

\footnotetext{
${ }^{5}$ Foucault has written at length about historical examples of this exercise of power/knowledge in terms of modern prisons (1979), medical clinics (1973), sexuality (1984), and madness (1965).
} 
International Journal of Child, Youth and Family Studies (2014) 5(2): 240-257

and images of "the homeless" and to help families recover and enlarge other ways of viewing themselves. (p. 329)

While providing individual, group, and family therapy was part of our role on the ACT team, Narrative Practices also informed the day-to-day interactions that we had with participants. For example, while delivering a person's medications, we also had opportunities to explore their hopes for the future. While assisting a person with budgeting and grocery shopping, we could bring forward unique outcomes. In the waiting rooms of medical clinics, we had opportunities to ask what advice a future version of oneself might give to the current version. If substance use had interfered with a person's tenancy, we could use externalization to explore the effects that substances were having on the person's life and those around them.

In some cases, a person had faced multiple evictions due to substance use and the problems that can accompany that, including noise complaints and the behaviour of guests. Drawing on Narrative Practices, we co-authored a mutual understanding document about our shared preferred outcomes for the person's housing, and the next steps to realizing this goal. This document was intended to set parameters and make expectations clear, while being as collaborative as possible. We were also aware that many programs with an addictions component required a formal assessment, which quantified a person's current substance use and history with various substances. In response, we developed a "Substance Use Conversation Template", which listed Narrative candidate questions borrowed from Colin Sanders, David Epston, Stephen Madigan, Vikki Reynolds, and others. These questions included:

- Have there been instances when [substance] convinced you to do something that went against your deeply held values? How did it do that?

- Were there other instances when [substance] tried to convince you to do something, but you stood by your values instead? How did you manage to take a stand in this instance?

- What response do you have for the direction that [substance] is taking your life?

- What is becoming possible that once seemed impossible, now that you've taken a few steps away from [substance]?

We selected questions for participants who were interested, and recorded their responses verbatim. We then co-authored a document about their relationship with substances, and gave a copy to them as an aid to transforming this relationship, if that was a preferred outcome. The person could refer back to this document later to track changes they had made.

The ethics of Narrative Practice infused the day-to-day choices we made, including our use of language with (and about) participants, our attempts to respect individuals as the experts in their own lives, and how we framed problems, such as making sure that we did not frame problems as residing within the bodies of individuals. 
International Journal of Child, Youth and Family Studies (2014) 5(2): 240-257

\section{The Context}

We worked in the city of Vancouver, Canada, on the unceded territories of Coast Salish peoples. Vancouver is known around the world for its Downtown Eastside (DTES), which is an area of several square kilometres infamous for its high concentration of social problems, flanked by expensive neighbourhoods and the downtown business core. Residents of the DTES ${ }^{6}$ have a long and interesting history of resistance, survival, and creativity.

Our team's task was to provide Housing First ACT services, rent supplements, and to give people the choice to move into apartments in different Vancouver neighbourhoods. Historically, people who have been homeless move through a continuum of shelters and housing offered in specific buildings (Mental Health Commission of Canada, 2013). In contrast, the Housing First ACT program used scatter-site housing, which are market apartments located in unidentifiable buildings around the city, in neighbourhoods chosen by the person who is going to live there. It is a form of housing not previously offered to homeless people in Vancouver. Over time, we observed that the vast majority of ACT participants chose housing outside the DTES.

In addition to Narrative Therapy, the principles guiding our work included participant choice, harm reduction, and mental health recovery. The authors had never personally experienced homelessness, nor been assigned labels such as schizophrenia or bipolar disorder. We knew we would not be able to offer advice or create a roadmap for people coming into the program. Instead, we approached our conversations with participants wondering, "What does this person have to teach me?” We noticed that this was a useful starting point as many people described past pathologizing and disrespectful experiences when their opinions and choices were not heard. Doing this kind of work is not a one-way process, with the worker "helping" and the "client" passively receiving. It tends to be a reciprocal process. Rather than charity, we try to remember that when you work in relationship with people, they have much to give you. We feel that we are now able to see further because of what we have been given.

Working in the context of the DTES required that we acknowledge the politics of the work, as the majority of front line workers have little formal qualifications relating to mental health or substance use, yet provide the majority of support provided to people in the DTES. Front line support workers in shelters, drop-in centres, and outreach programs deal with the most difficult and intense situations and are often overworked, undervalued, and underpaid, in addition to having to "help" individuals experiencing problems that are systemic in nature. The requirement to have an educational qualification and the professionalization of human service work can serve to separate front line workers from the very skills they need to have useful and supportive conversations. Hansen (2010) describes how the rewards of the rise of professionalism in the field of counselling have limited the discussion of some of the disadvantages of professionalism, including insularity. We are not implying that training and education are not important. Rather, we seek to deconstruct the existing notions of what it takes to be useful in relationship, and not add to an anxiety telling us that we are not good enough workers. Some of the best work we have witnessed has been by non-credentialed staff, who are able to sit with people in distress, listen with the utmost respect and curiosity, and who can

\footnotetext{
${ }^{6}$ To learn more about the social and political history of this area, see A Thousand Dreams by Larry Campbell, Neil Boyd, and Lori Culbert (2009).
} 
International Journal of Child, Youth and Family Studies (2014) 5(2): 240-257

refrain from telling clients what to do. This position of non-expert listener serves as the most useful foundation in our work.

\section{Key Concepts}

Key concepts of Narrative Therapy we used while working with the RainCity Housing First ACT Team, include: seeing the person as expert; recontextualizing the problem; externalization; story as a metaphor; and re-authoring.

\section{Person as the Expert in Her or His Own Life}

In Narrative Practice we attempt to reverse the traditional power dynamic, and privilege insider knowledge rather than "expert" professional knowledge, while also endeavouring to acknowledge the inherent imbalance of power in the relationship as a result of our privilege (e.g., from education, class, race, sexual identity, and gender). In this sense, our expertise is not so much about telling people what they need to do to make a change (in this case, from homelessness to having a home), but rather working towards dismantling barriers and constraints, all the while treating people with respect, and being skilful and compassionate in the kinds of questions we ask. Our role is to facilitate individual and group conversations, with the aim of bringing into the foreground the knowledge, capacities, experiences, values, ethics, and connections required to make new meaning and change. We have learned that at both a group and an individual level, it is more ethical and pragmatic to centre people as experts in their own lives. To illustrate the value of insider knowledge, we have included the following exchange between Roy and co-author Brian at a training session for service providers:

Brian: Do you have any other advice for people interacting with people having these kinds of struggles?

Roy: You're not going to be able to convince people - they all know: I need ID, education, a job ... they know, it's just that they're not ready ... and workers sometimes get worked up by something that their client says, and "I can't help you unless you see it this way" and [the person]'s not going to see it that way...

As we began our ACT work, we attempted a non-expert position and began interviewing those who came to a weekly group, which came to be known as "Becoming an Insider". The meaning of the group's name was twofold: first, people's experiences of literally moving inside after a period of homelessness, and secondly, a shift in identity away from being people with undervalued or marginalized knowledge, towards being people with insider knowledge that was both valued and centred. We asked participants about their experiences of homelessness, the mental health system, their substance use, and what skills and knowledge they were now using in order to create a home. We acknowledged the value of this insider knowledge by archiving it as a handbook for staff and for new participants, similar to the handbook created with homeless families living in New York City shelters, as described by Fraenkel et al. (2009). We also developed a newsletter based on the content of these discussions, and circulated the insider knowledge to other participants outside the group. 
International Journal of Child, Youth and Family Studies (2014) 5(2): 240-257

As we became aware of the isolation and lack of support that family members of participants were feeling, a group for family members began. The Family Group fostered relationships around shared experiences and explored the many ways family members had stood by their loved ones in the face of poverty, social stigma, mother-blaming practices, and violence. $^{7}$

In our experience, centering people as experts in their own lives helped in creating rapport and close relationships with the people we were allying with. It was the rich quality of these relationships that served workers and participants alike, particularly when challenges and/or conflict arose. As a deeply respectful and collaborative approach, Narrative Practices are particularly well suited to cultivating collaborative working relationships and fostering a therapeutic alliance. The centering of insider knowledge is not just a token gesture, but can have powerful effects on the lives of insiders and even on the institutional systems that surround them, notably when given the opportunity to build solidarity and community with others who are facing similar struggles.

\section{Re-contextualizing Problems and Resisting the Blaming of Individuals}

It seems obvious to state that homelessness, substance use dilemmas, and mental health struggles are entwined within a matrix of cultural, social, political, and economic forces. As Tilsen (2013) asks: "If we understand problems to be socially located and that discourse shapes and gives meaning to personal narratives, is it possible or ethical to only work on the micro level with clients?” (p. 102). However, dominant psychological discourses about these problems have suffered from a narrow focus on individual experience, and at times this has inadvertently led to the blaming of individual bodies as the source, and container, of these problems (Morrow \& Weisser, 2012). Narrative Therapy, drawing as it does on academic disciplines with a broader focus (sociology, anthropology, cultural studies, gender studies, and women's studies), can remind workers of the landscape in which the day-to-day struggles that they encounter are contained. Keeping this in the foreground of our work creates space for us to resist the blaming of individuals when we are faced with persistent problems, behaviours, or interpersonal patterns in the complicated world of front line service work. White \& Epston (1990) write: "Within the context of the practices associated with the externalizing of problems, neither the person nor the relationship between persons is the problem. Rather, the problem becomes the problem, and then the person's relationship with the problem becomes the problem.” (p. 40).

As wealth has become concentrated in fewer and fewer hands, the social safety net and national housing program have also been shredded over the past two decades in Canada, which remains one of a few countries without a national housing strategy, or an official definition of homelessness. ${ }^{8}$ If homelessness, substance use, and/or mental health challenges are framed by the media and politicians as a personal "choice”, it has the effect of further absolving society

\footnotetext{
${ }^{7}$ The authors will examine these narrative groups in greater detail in an article currently in progress entitled, Becoming an insider: Narrative therapy groups alongside people overcoming homelessness.

${ }^{8}$ See report by Special Rapporteur Miloon Kothari to United Nations Human Rights Council in 2009, based on a 2007 tour of Canada: http://www.lubicon.ca/pa/humanrp/un090217.htm
} 
International Journal of Child, Youth and Family Studies (2014) 5(2): 240-257

from collective responsibility for making things better for everyone. Pejorative terms for people with these kinds of struggles obscure the context of trauma, social inequality, racism, sexism, homophobia, and various other factors that contribute to homelessness (Boyer, Ku, \& Shakir, 1997; Kirmayer, Brass, \& Tait, 2001; Mental Health Commission of Canada, 2009; all as cited in Morrow \& Weisser, 2012), and blame the individual for their plight due to their lack of effort or character. Narrative Therapy reminds us to be cognizant, even vigilant, about the context from which these kinds of problems arise and, as a practice, it holds promise as a form of "justicedoing” (Reynolds \& polanco, 2012).

A significant aspect of our work was re-contextualizing problems. In therapeutic conversations with the person, we brought forward the context that supported the problems they were facing. We discovered that when asked, people were often happy and even relieved to be asked these kinds of questions. We found that substance use was in some instances a reasonable response to experiences of trauma. Ongoing experiences of violence and stigma related to transphobia had constrained housing and career options. Alcohol use, rather than reflecting a personal failing or character defect, could be fuelled by the legacy of racism, genocide, residential schools, and related abuses in Canada against First Nations peoples. We asked questions with the intention of exposing various oppressive social forces that supported problems, and also questions that reminded the person of the resources and support that they had to resist or counter the problem. For example:

- How did racism / sexism / transphobia / homophobia / ableism make using crack cocaine an easier option for you to take up?

- Did growing up in a working family that struggled to make ends meet make anxiety stronger or weaker for you? How did it do that?

- What is the relationship between homelessness and crystal meth use? How did your use of meth make homelessness more manageable? Was there a turning point when meth started to fuel homelessness more than it was fuelling you?

- How did social stigma about your schizophrenia diagnosis affect the job options that were available to you?

- Who knows about your ability to resist the influence of depression? What might they tell me they know about you that leads them to believe you can overcome it?

- Who stands with you now against psychosis, and how might we invite them to get more involved in supporting you?

Narrative Practices help us resist the temptation to blame individuals for these problems, helping us to ally with the person and build rapport. It also allows the person to see the problem and themselves in a different light - supporting them in developing an alternative story, reauthoring a new identity, and moving their life in a preferred direction.

\section{Externalization}

While living in Australia, co-author Barbara had the opportunity to hear the late Michael White, one of the co-creators of Narrative Therapy, speak on numerous occasions. She heard him 
International Journal of Child, Youth and Family Studies (2014) 5(2): 240-257

repeatedly emphasize that externalization is not a skill, but rather an ethic (White \& Epston, 1990), or an attitude (Roth \& Epston, 1996). White deeply believed that people were not problems. He suggested using externalization as a means to ensure problems remain separately located - outside of the individual and in the realm of culture. Problem identities have been constructed in a societal context and thus must be examined and considered in the same context (White, 1995).

Externalizing helps to ensure that our work is different from colonizing practices, which seek to blame, pathologize, and control an individual. Approaching our community work with the belief that people are not problems, and that the problems of an unjust society should not be individualised onto a person, is a form of social justice. By separating the problem, what contributed to its creation, and how the person has responded to it, we can reinforce the idea that problems are not people. By locating a problem outside a person or their identity, people have space to consider the problem and their relationship to it, deconstruct the problem, and reflect on possible actions they might take.

In the Narrative tradition, when we write letters to people about problems, we use capitals to denote the problem, which helps to emphasize that the person and problem are separate entities. Similarly, we change the adjectives people use as self-descriptors into nouns. For example, if someone talks about "being an angry person", we might ask, "how long has Anger been a big part of your life?” In our learning and teaching, we have asked people to interview each other about the role of a minor substance - for example, caffeine or chocolate - in their life, using the following example questions:

- In what ways has [Substance] been a friend to you?

- How have you experienced it as helpful to your mental health or otherwise?

- Are there any ways that [Substance] has interfered in your life? Are there any drawbacks to it?

- Have there been any instances where you have changed or challenged [Substance's] influence in your life? What led up to this step?

Practicing externalizing questions invites people to explore the subject from a new position of curiosity, rather than from an assumption that the Substance is entirely bad. We find that externalizing conversations that equally explore advantages and disadvantages of substance use are unique and useful for people who experience co-occurring problems in mental health and substance use. It is useful to us as workers, because it maintains the focus of the conversation on exploring the person's relationship with the Substances, and helps to safeguard us from attempting to convince people to abandon their substance use. Externalization shows up in our conversation with Roy about the current impact of substances in his life:

Roy: You can't do that all your life [Dope], you get old, your body starts falling apart. I'm not 22 anymore, I get more hung over now.

Brian: So is it just being more hung over that has gotten you to make some changes with Dope?

Roy: Yeah, the effect the next day, even just being older - now you got $\$ 60$ worth of dope in your system, it makes it that much harder. There's other ways to enjoy your life 
International Journal of Child, Youth and Family Studies (2014) 5(2): 240-257

Brian: Like what?

Roy: Like, go to a concert. I've got my guitar now, playing since 16 on and off

Brian: Were you separated from music for a while?

Roy: Yeah, there was nowhere I could play. It's hard when you're outdoors trying to keep warm.

Brian: How did you reclaim the musician part of yourself?

Roy: A friend played guitar and I picked it up one day. I enjoyed it, so got my own.

Brian: Does the guitar separate you further from Substances?

Roy: Yeah. And having a group of people encouraging me is better than people saying

I'm a junkie. I have Dual Diagnosis, Mental Health Issues, plus Substance Abuse, plus

Trauma from living on the streets.

Externalization can also be useful when exploring people's symptoms of mental health problems or trauma. Many people attending our group reported being given a label or diagnosis without consultation or explanation, compounding a sense of disconnection from the agencies and workers that are supposed to provide support. Exploring the content of hearing Voices, for example, can lead to powerful and useful understanding of their meaning (Hearing Voices Network, n.d.), which is a contrast from how people have been repeatedly told to ignore voices or take medication to dampen them, compounding the isolation and shame a person may already be experiencing. Here are some enquiring externalizing questions regarding Schizophrenia and the experience of hearing Voices:

- Which parts of Schizophrenia can you relate to?

- Are there some parts of Schizophrenia that don't fit for you?

- Could you tell me about parts of your life that aren’t influenced by Schizophrenia?

- When you experience Voices, how do you respond to them?

- Are there times when ignoring the Voices works better than others?

- What are some of the tactics that Voices use to try to get control over you?

- If the Voices succeed in convincing you that you are a bad person, how do you imagine this will influence the direction your life takes?

Personifying a problem such as "Voices" creates space for a person to revise their relationship with the problem (White, 1995). Our aim is not to eradicate the Voices, as there are some problems that we cannot eliminate, but rather to explore and revise the meaning of the problem. In this way, the person's own knowledge of a problem or experience (as opposed to professional knowledge) is privileged and at the centre of the conversation. Utilizing a Narrative approach, including externalizing, helps us as workers and as community members ensure that community problems are framed as social justice issues. Freedman and Combs (1996) frame this as an ethical practice. White (1995) also suggests that externalization is useful for examining the dominating and subjugating ideas about mental health and what it takes to be a worthy and "normal person".

\section{Story as Metaphor}

Narrative Practice uses the idea of story as a metaphor to describe how people create a sense of who they are and the actions they take (White \& Epston, 1990). For this purpose, story 
International Journal of Child, Youth and Family Studies (2014) 5(2): 240-257

means a series of events linked in sequence, across time, according to a plot (Morgan, 2000). People can have cultural and contextual stories about who they are (Freedman \& Combs, 1996), and both can be dominant or subordinate stories. In this sense, we are multi-storied (Madigan, 2011; White \& Epston, 1990). Stories told and retold shape us as individuals and as groups of people. Societies tell the story of homelessness in a variety of ways. For example, newspapers tell the story of one person's experience with becoming homeless, often noting that the person was abused, didn't finish school, and perhaps fell into drug use. This kind of media story does not outline the lack of a national housing strategy (in Canada), the low income people receive (if they are deemed eligible) when they are homeless, the lack of available, affordable, and safe housing, the impact of colonization and loss of culture for an Aboriginal or Metis person, or how using substances when living outdoors is part of a broader process to form relationships and survive living rough or in substandard housing. Instead, society tells the story of an individual with flaws, who is considered a failure. This story is often taken up by the person, pushing aside stories of their own worth, values, and hopes for themselves, their community, and future.

Co-author Barbara had the opportunity to meet a participant we will call Bill, who had secured housing through our program. She suggested they get coffee and have a chat at a bakery near his home. Barbara was familiar with this new bakery, and noted that they took pride in the French style they had developed. Bill had also noticed this new bakery opening in his community. Before agreeing to a coffee, Bill asked if it was okay if he entered the bakery. He explained, “Well, I just worry that I might smell and I don't look okay enough to go in there”. We can use his question to examine the stories being told about Bill, as well as deconstruct the dominant ideas that might impact how he relates to his community. Below are a few questions we could consider asking to highlight the layers of dominant and subordinate stories interwoven in this simple moment: Bill had lived in this neighbourhood for many years when he was homeless, long before this bakery was opened. We might wonder about who gets to determine who belongs in this neighbourhood.

- What other acts of gentrification were taking place in the neighbourhood that led up to Bill deciding he might not be welcome in the bakery?

- What experiences of discrimination had Bill experienced (while he was homeless or housed) which supported his self-exclusion?

- What were Bill's thoughts on what it takes for a person to be "okay enough" to access a business? What dress, standard of hygiene, volume/tone of voice, or movement of his limbs was required?

- What was Bill taking a stand for in his uncertainty about going into the bakery?

- How had Bill stood up to this kind of stigma in the past?

As workers, we want to support people in telling the stories of their life, but a simple telling is not necessarily useful because it might reinforce a less helpful or pathologizing story. For example, if we simply ask Bill to tell us about all the times he was excluded from businesses, 
International Journal of Child, Youth and Family Studies (2014) 5(2): 240-257

we won't necessarily discover a subordinate narrative ${ }^{9}$. By asking Bill about his experiences, how he responded to these experiences, and his thoughts on the context of these stories of his life, we will hear more about the things he values. We will hear stories about how he prefers to live his life, and his hopes for the future. By deconstructing the cultural or meta-stories of what it means to be homeless, we ensure that the context of homelessness is not individualized onto a person. For people with multiple problem stories of intersecting oppression, it is our duty to ensure that these problems are given light in a wider context beyond the person.

\section{Re-authoring}

When working with individuals living at the intersections of multiple social inequities, our individual support work becomes community work. If we accept that our work with people is to deconstruct the problems that have been created in a context of social injustice, then telling the under-told story of how they have resisted the problem or limited its influence is a necessary step, one which has been called re-authoring. Michael White (2005) wrote:

Re-authoring conversations invite people to do what they routinely do - that is, to link events of their lives in sequences through time according to a theme/plot. However, in this activity, people are assisted to identify the more neglected events of their lives - the unique outcomes or exceptions - and are encouraged to take these into alternative story lines. (p. 10)

Telling an alternative or counter story about ourselves different from the dominant story can be a radical act, especially in the oppressive context of being told we are damaged and in need of repair. In human service and support work, we are trained to look for symptoms and signs of problems or pathology. In a search to understand how people are not doing "well”, we end up overlooking all the ways they are living well despite the problems they are experiencing. White (2005) encourages us to listen to a person's problem story, but more importantly, to seek out the stories of how people responded to problems and how they resisted problems from completely taking over their lives. White also suggests that no one problem could completely take over a person's life. There are always areas of living or moments where the problem had little or no influence. White would focus on these places with great curiosity. For example, when Roy talks about not using Dope for two days, we take a moment to explore this action with questions such as:

- How did you go for two days without Dope?

- Was this an important step that you took?

- Can you tell me what led up to it?

- What did you do to prepare yourself to be without Dope?

- If you continued to loosen Dope's grip on your life each day, what possibilities might open up?

${ }^{9}$ Subordinate narrative: stories located outside the cultural, professional, and problem's version of a person (Madigan, 2011, p. 83). 
International Journal of Child, Youth and Family Studies (2014) 5(2): 240-257

When Roy answers these kinds of questions, we hear about his love for music, food, going to the movies, and about his ethic to help others. All of these answers can be explored as possible storylines, narratives that have been overshadowed by the dominant stories of being a “mental patient” or "addict”. Similarly, by asking questions that explore unique outcomes, we hear a rich and moving description of Roy's hope for his future, including what support he needs to get there:

Barbara: Any advice you'd share with your future self?

Roy: You're asking about the direction I'm heading?

Barbara: What do you call that?

Roy: Up to the highest peak, not taking a way out - the highest point of achievement that I can - right now it's music, later on with school, to learn as much as I can, fulfill my destiny given to me by my ancestors and my higher power. The reward for me if I choose to go this way - if I climb up to the spot where I need to be, it will be easier for me to slide down the hill.

By exploring how people have responded to the problems in their life, other untold stories or unique outcomes come to light. For example, Roy as a person with significant experience with Dope, has very likely had multiple experiences of going to substance use treatment, detox, or recovery facilities. Each of those steps of resisting Dope could be explored. Doing this might tell a larger story of his preferences for his life, or of his tenacity in not giving in fully to Dope's control, or letting Dope overshadow his own preferences for life. In this way we ensure that Roy's own knowledge is at the centre of the conversation, and that we as workers are not simply telling him what his new story of self should be.

\section{Roy's Reflection}

Brian met with Roy over coffee in July 2013 to go over this article and give him the opportunity to respond and reflect on what we have written. We also discussed whether he would like to be published as a co-author. Roy declined this option, choosing to use a pseudonym to maintain his privacy, but consented to having us use his de-identified words and story so that others could benefit. Here are some excerpts from the conversation:

Brian: As you were listening to me read the article, which parts caught your attention? Roy: It was a reminder of back when I was doing the interview in front of the audience [a workshop in January 2013], I forgot about half the stuff we actually talked about.

Brian: So was that a good kind of remembering, or ...?

Roy: Yeah, yeah.

Brian: What was good about it?

Roy: It was good to remember where you been, right?

Brian: Is that a place that you'd like to go back to?

Roy: Things have changed since then. I feel like I'm a totally different person since that time.

Brian: How have you become a different person?

Roy: Dope isn't a part of my life anymore ... I'm working on a new plan here. I'm not too sure where I'm going, but it's a different direction that's for sure. 
International Journal of Child, Youth and Family Studies (2014) 5(2): 240-257

Brian: Is there anything that you think would be important for us to add to this article that we missed or forgot to mention?

Roy: I think you've covered it all.

Brian: What else has changed for you since we did this interview back in January?

Roy: Just a different outlook on life. Different tastes. In a dilemma of "what am I going to spend my money on now?”

\section{Conclusion}

Implementing models of Assertive Community Treatment and Housing First, the authors and their colleagues drew upon the respectful practices of Narrative Therapy when joining participants in their journeys from homelessness to being housed, and to consider their relationships with substance use. Narrative practices opened space for new conversations about a person's experiences of their mental health and to make new meanings of these experiences, as have been shown by others working in youth homelessness (Hartman et al., 2008), families living in homeless shelters (Fraenkel et al., 2009), and with youth struggling to overcome substance use (Sanders, 1998, 2007). Front line workers, often dealing with the most difficult situations, may benefit from learning the principles of Narrative Practices to support their work.

Working in the intersections of poverty, colonization, substance use, homelessness, and mental illness, workers might feel out of their depth as we have traditionally been taught in human service degrees to "have the answer", thereby obscuring the wisdom of the people we are paid to support and further marginalizing their voices. In this paper, the authors suggest that by using key concepts of Narrative Therapy - including seeing the person as expert; recontextualizing the problem; externalization; story as a metaphor; and re-authoring - workers will see further and be able to support the telling of a person's hopes, dreams, and untold abilities.

The authors believe that Narrative Therapy is a socially just response to community problems that have been unfairly individualized onto people who have survived trauma and institutional violence. By deconstructing the social context and history of problems, individual responsibility is abdicated, breathing further life into stories of resistance, determination, wisdom, and hope. As Roy described, we continue to "head towards the highest peak" to view what has previously been unseen. 
International Journal of Child, Youth and Family Studies (2014) 5(2): 240-257

\section{References}

Campbell, L., Boyd, N., \& Culbert, L. (2009). A thousand dreams: Vancouver's downtown eastside and the fight for its future. Vancouver, BC: Greystone Books.

Dulwich Centre Publications (n.d.). Commonly-asked questions about narrative approaches to therapy, community work, and psychosocial support. Retrieved from http://dulwichcentre.com.au/common-questions-narrative-therapy.html

Foucault, M. (1980). Power/knowledge: Selected interviews and other writings. New York, NY: Pantheon.

Fraenkel, P., Hameline, T., \& Shannon, M. (2009). Narrative and collaborative practices in work with families that are homeless. Journal of Marital and Family Therapy, 35(3), 325-342. http://dx.doi.org/10.1111/j.1752-0606.2009.00119.x

Freedman, J., \& Combs G. (1996). Narrative therapy: The social construction of preferred realities. New York, NY: Norton.

Hansen, J. (2010). Ideas on the margins: Professional counseling and ideological insularity. International Journal for the Advancement of Counselling, 32(3), 214-224. http://dx.doi.org/10.1007/s10447-010-9102-4

Hartman, L., Little, A., \& Ungar, M. (2008). Narrative-inspired youth care work within a community agency. Journal of Systemic Therapies, 27(1), 44-58. http://dx.doi.org/10.1521/jsyt.2008.27.1.44

Hearing Voices Network. (n.d.) About hearing Voices network: A new approach. Retrieved from http://www.hearing-voices.org/about-us/

Kothari, M. (2009). Promotion and protection of all human rights, civil, political, economic, social and cultural rights, including the right to development (Report of the special rapporteur on adequate housing. Addendum: Mission to Canada, October 9-22, 2007). New York: United Nations General Assembly.

Madigan, S. (2011). Narrative therapy. Washington, DC: American Psychological Association.

Matejkowski, J., \& Draine, J. (2009). Investigating the impact of Housing First on ACT fidelity. Community Mental Health Journal, 45, 6 - 11. http:/dx.doi.org/10.1007/s10597-008-9152-9

Mental Health Commission of Canada (2013). Turning the key: Assessing housing and related supports for persons living with mental health problems and illness. Retrieved from http://www.mentalhealthcommission.ca/English/node/562?terminitial=41

Mental Health Commission of Canada (2012, January). At Home / Chez Soi early findings Report: Volume 2. Retrieved from http://www.mentalhealthcommission.ca/English/node/775?terminitial=23 
International Journal of Child, Youth and Family Studies (2014) 5(2): 240-257

Morgan, A. (2000). What is narrative therapy? An easy-to-read introduction. Adelaide, Australia: Dulwich Centre.

Morrow, M. \& Weisser, J. (2012). Towards a social justice framework of mental health recovery. Studies in Social Justice, 6(1), 27-43.

polanco, m. (2011). Autoethnographic means to the ends of translating/decolonizing narrative therapy: The birth of terapia solidaria [therapy of solidarity] (Unpublished doctoral dissertation). Ft. Lauderdale, Florida: Nova Southeastern University. http://dx.doi.org/10.1521/jsyt.2011.30.3.42

Reynolds, V. (2010). A supervision of solidarity. Canadian Journal of Counselling, 44(3), 246257.

Reynolds, V. \& polanco, m. (2012). An ethical stance for justice-doing in community work and therapy. Journal of Systemic Therapies, 31(4), 18-33. http://dx.doi.org/10.1521/jsyt.2012.31.4.18

Roth, S. \& Epston, D. (1996). Consulting the problem about the problematic relationship: An exercise for experiencing a relationship with an externalized problem. In M. Hoyt (Ed.), Constructive therapies: Volume 2 (pp. 148-162). New York, NY: Guilford.

Sanders, C. J. (1998). Substance misuse dilemmas: A postmodern inquiry. In S. Madigan \& I. Law (Eds.), Praxis: Situating discourse, feminism \& politics in narrative therapies (pp. 141-162). Vancouver, Canada: Cardigan Press.

Sanders, C.J. (2007). A poetics of resistance: Compassionate practice in substance misuse therapy. In C. Brown \& T. Augusta-Scott (Eds.), Narrative therapy: Making meaning, making lives (pp. 59-77). Thousand Oaks, CA: Sage. http://dx.doi.org/10.4135/9781452225869.n4

Tilsen, J. (2013). Therapeutic conversations with queer youth: Transcending homonormativity and constructing preferred identities. Lanham, MD: Jason Aronson.

Tsemberis, S. (2010). Housing First: The Pathways model to end homelessness for people with mental illness and addiction. Centre City, MN: Hazelden.

Turnbull, H.W. (Ed.). (1959). The correspondence of Isaac Newton, Volume 1 (1661-1675). Cambridge, MA: University Press.

White, M. (1995). Re-authoring lives: Interviews and essays. Adelaide, Australia: Dulwich Centre.

White, M. (2005). Workshop notes. Retrieved from http://www.dulwichcentre.com.au/michaelwhite-workshop-notes.pdf

White, M., \& Epston, D. (1990). Narrative means to therapeutic ends. New York, NY: Horton. 